UDC 69.001.5

Author: KUDRYAVTSEV Pavel Gennadievich, Professor, D.Sc., Leading Researcher Polymate Israel Research Center (Israel), Academician of International Academy of Sciences for Ecology and Human Safety and Russian Academy of Natural Sciences, Author of 207 scientific works, including 4 monographs, has 34 inventions. He was awarded the M.V.Lomonosov medal, Commander of the Order «The Star of the Scientist» and was awarded the honorary title «Honored Worker of Science», awarded the medal of P.A. Stolypin, and honorable diamond sign of the Chamber of Commerce and Industry of the Russian Federation. Polymate Ltd. - Israel Research Center, POBox 73, Migdal HaEmek 10550, Israel, e-mail: pgkudr89@gmail.com;

Author: FIGOVSKY Oleg Lvovich, Professor, Full Member of European Academy of Sciences, Foreign Member of REA and RAASN, Editor-in-Chief of Journals SITA (Israel), OCJ and ICMS (USA), Director for Research and Development Polymate - Israel Research Center (Israel) and Nanotech Industries Inc., (USA); Chairman of the UNESCO chair «Green Chemistry»; President of Israel Association of Inventors; Laureate of the Golden Angel Prize, Commander of the Order «Engineering glory» (Russia) and «Leading Intellectuals of the World» (USA). Polymate Ltd. - Israel Research Center, POBox 73, Migdal HaEmek 10550, e-mail: figovsky@gmail.com

\title{
HEAT-RESISTANT INORGANIC BINDERS
}

\section{Extended Abstract:}

The authors consider some aspects of production of inorganic heat-resistant composite materials in which new classes of inorganic binders - the basic salts of various metals - are applied. The possibility to use hydroxochlorides and hydroxonitrates of aluminum, zirconium, chromium and a number of other metals as the binder has been shown. The main products of the thermal decomposition of all types of binders discussed in this paper are nano-dispersed highly refractory oxides. Increased pressure in the manufacture of these materials shifts the position of the minimum of the dependence "production strength - production temperature» in the direction of low temperatures. This effect is caused by decreased film thickness of the binder located between filler particles and hence by increased rate of transfer of the matter to the interface and by facilitated sintering process. Materials based on the systems containing chromium and some other elements in transitional oxidation states are colour. For this reason, they have the worst thermal conductivity under the same heat resistance compared to colorless materials.

Key words: Inorganic binders, basic aluminum salts, basic salts of transition metals, inorganic composites, heat resistant materials. 
MACHINE-READABLE INFORMATION ON CC-LICENSES (HTML-CODE) IN METADATA OF THE PAPER

$<$ a rel="license" href="http://creativecommons.org/licenses/by/4.0/"><img alt="Creative Commons License" style="borderwidth:0" src="https://i.creativecommons.org/l/by/4.0/88x31.png" $/></ \mathrm{a}><$ br $/><$ span xmlns:dct="http://purl.org/dc/ terms/" href="http://purl.org/dc/dcmitype/Text" property="dct:title" rel="dct:type" $>$ Heat-resistant inorganic binders $</$ span> by <a xmlns:cc="http://creativecommons.org/ns\#" href="Nanotehnologii v stroitel'stve = Nanotechnologies in Construction. 2017, Vol. 9, no. 2, pp. 66-81. DOI: dx.doi.org/10.15828/2075-8545-2017-9-2-66-81. (In Russian). " property="cc:attributionName" rel="cc:attributionURL" $>$ Kudryavtsev P.G., Figovsky O.L. $</ \mathrm{a}>$ is licensed under a $<\mathrm{a}$ rel="license" href="http://creativecommons.org/licenses/by/4.0/">Creative Commons Attribution 4.0 International License $</ \mathrm{a}>.<\mathrm{br} />$ Based on a work at $<$ a xmlns:dct="http://purl.org/dc/terms/" href="http://nanobuild.ru/en_EN/ nanobuild-2-2017/" rel="dct:source" >http://nanobuild.ru/en_EN/nanobuild-2-2017/</a $>$. $<$ br $/>$ Permissions beyond the scope of this license may be available at $<$ a xmlns:cc="http://creativecommons.org/ns\#" href="pgkudr89@gmail.com" rel="cc :morePermissions">pgkudr89@gmail.com $</ \mathrm{a}>$.

\section{References:}

1. Figovsky O., Beilin D. Advanced Polymer Concretes and Compounds @ CRC Press, Tailor \&Francis Group, 2013, 245 pp.

2. Kudryautsev P.G., Volkhin V.V. Zol'-gel' processy i nekotorye ego tehnologicheskie prilozhenija, zol'-gel' processy poluchenija neorganicheskih materialov: tez. dokl. seminara [Sol-gel processes and some of its technological applications. Sol-gel processes of obtaining inorganic materials]. Theses of reports of the seminar, Perm, 1991, p. 3-5. (In Russian).

3. Kudryavtsev P.G., Kavalerova O.B. Metody poluchenija zolej oksigidratov metallov, ispol'zuemyh $\mathrm{v}$ kachestve svjazujushhih dlja formovanija neorganicheskih kompozitov [Methods for producing metal oxyhydrate sols used as binders for forming inorganic composites]. Collection of scientific papers. Composite materials based on disperse systems. Ekaterinburg: UrO RAN, 1994, pp. 21-29. (In Russian).

4. Kudryavtsev P.G., Kavalerova O.B., Kazakova I.L., Volkhin V.V. Poluchenie i stabilizacija rastvorov oksidov metallov [Preparation and stabilization of solutions of metal oxides]. Workshop: Sol-gel processes of inorganic materials production, Perm, 1991, p. 33. (In Russian).

5. Poluchenie oksida aljuminija osoboj chistoty: obzornaja informacija [Production of aluminum oxide of special purity: overview]. Series: Reagents and extra pure substances. Moscow, NIITCHIM, 1987, 40 p. (In Russian).

6. Kudryavtsev P.G. Alkoxides of chemical elements - promising class of chemical compounds wich are raw materials for Hi-Tech industries; Journal «Scientific Israel - Technological Advantages», Vol. 16, N 2, 2014, p. 147-170.

7. Evans K.A. Properties and uses of aluminium oxides and aluminium hydroxides, in The Chemistry of Aluminium, Indium and Gallium, ed. A.J. Downs, Published by Blackie Academic, 1993, ISBN 075140103 X. 
8. Journal of Applied Chemistry, 1969, vol. 12, No. 6, p. 1325-1330.

9. Komarova T.I., Korneeva T.F. Poluchenie svjazki na osnove 5/6 oksihlorida aljuminija [Obtaining a binder based on 5/6 aluminum oxychloride. In the collection: Non-building binders]. Leningrad, 1975, p. 52-56. (In Russian).

10. Sychev M.M. Neorganicheskie klei [Inorganic adhesives]. $2^{\text {nd }}$ ed., Leningrad, Chemistry, 1986, 152 p. (In Russian).

11. Inorganic Materials, 1979, v. 15, No. 1, p. 2067-2069.

12. Izvestiya high schools. Chemistry and Chemical Technology, 1982, v. 25, no. 6, p. 740-743.

13. Journal of Applied Chemistry, 1969, v. 13, No. 7, p. 1485-1490.

14. Cement, 1975, No. 3, p. 9-10.

15. Inorganic Materials, 1978, v. 14, No. 6, p. 1153-1155.

16. Fizicheskaja himija i tehnologija silikatnyh materialov [Physical Chemistry and Technology of Silicate Materials], Leningrad: LTI, 1978, no. 6, p. 113-118. (In Russian).

17. Data published annually by World Aluminium, London. Available at: http://www. world-aluminium.org.

18. Figovsky O., Kudryavtsev P. Advanced Nanomaterials Based On Soluble Silicates. Journal «Scientific Israel - Technological Advantages», Vol. 16, N 3, 2014, p. 38-76.

19. Kudryavtsev P.G., Figovsky O.L. Nanostrukturirovannye materialy, poluchenie i primenenie v stroitel'stve [Nanostructured materials, production and application in construction]. Nanotechnologies in construction. 2014. Vol. 6, No. 6. p. 27-45. DOI: dx.doi.org/10.15828/2075-8545-2014-6-6-27-45 (In Russian).

\section{DeAR COLleagues!}

THE REFERENCE TO THIS PAPER HAS THE FOLLOWING CITATION FORMAT:

Kudryavtsev P.G., Figovsky O.L. Heat-resistant inorganic binders. Nanotehnologii v stroitel'stve $=$ Nanotechnologies in Construction. 2017, Vol. 9, no. 2, pp. 66-81. DOI: dx.doi.org/10.15828/2075-8545-2017-9-2-66-81. (In Russian).

Contact information
Figovsky Oleg Lvovich

figovsky@gmail.com 
уДК 69.001.5

Автор: КУДРЯВЦЕВ Павел Геннадьевич, профессор, D.Sc., ведущий научный сотрудник

Polymate - Israel Research Center (Израиль), действительный член (академик) МАНЭБ и РАЕН, автор 207 научных работ, в том числе 4 монографий, имеет 34 изобретения, награжден медалью им. М.В. Ломоносова, кавалер ордена «Звезда Ученого», удостоен почетного звания «Заслуженный деятель науки», награжден медалью П.А. Столыпина и почетным бриллиантовым знаком Торговопромышленной палаты РФ; РОВох 73, Migdal HaEmek, Polymate Ltd. - Israel Research Center, 10550, Израиль, e-mail: pgkudr89@gmail.com;

Автор: ФИГОВСКИЙ Олег Львович, профессор, действительный член Европейской академии наук, иностранный член РИА и PAACH, главный редактор журналов SITA, OCJ и RPCS, директор по науке и развитию Polymate - Israel Research Center (Израиль) и Nanotech Industries Inc. (USA), зав. кафедрой ЮНЕСКО «Зелёная химия», президент Израильской ассоциации изобретателей, лауреат Golden Angel Prize, кавалер орденов «Инженерная слава» (Россия) и «Leading Intellectuals of the World» (USA); POBox 73, Migdal HaEmek, Polymate Ltd. - Israel Research Center, 10550, Израиль, e-mail: figovsky@gmail.com

\section{НЕОРГАНИЧЕСКИЕ ТЕРМОСТОЙКИЕ СВЯЗУЮЩИЕ}

АННОТАЦИЯ К СТАТЬЕ (АВТОРСКОЕ РЕЗЮМЕ, РЕФЕРАТ):

В настоящей работе рассмотрены вопросы получения неорганических термостойких композиционных материалов с использованием новых классов неорганических связующих - основных солей различных металлов. Показана возможность использования в качестве связующего гидроксо-хлоридов и гидроксо-нитратов алюминия, циркония, хрома и ряда других металлов. Основными продуктами термического разложения всех типов связующих, рассмотренных в настоящей работе, являются нанодисперсные высокоогнеупорные оксиды. Повышение давления при изготовлении данных материалов сдвигает положение минимума на зависимостях прочность - температура изготовления в сторону низких температур. Этот эффект обусловлен уменьшением толщины пленки связующего между частицами наполнителя и, соответственно, увеличением скорости переноса вещества к межфазной границе и облегчению процессов спекания. Материалы на основе систем, содержащих хром и некоторые другие элементы в переходных степенях окисления, имеют окраску. Вследствие этого они имеют худшие показатели по теплопроводности при одинаковой термостойкости, по сравнению с бесцветными материалами. 
Ключевые слова: неорганические связующие, основные соли алюминия, основные соли переходных металлов, неорганические композиты, термостойкие материалы.

DOI: dx.doi.org/10.15828/2075-8545-2017-9-2-66-81

МАшИНОЧИТАЕМАЯ ИНФОРМАЦИЯ о CC-лИЦЕНЗИИ В МЕТАДАННЫХ СТАТЬИ (HTML-код):

$<$ a rel="license" href="http://creativecommons.org/licenses/by/4.0/"><img alt="Лицензия Creative Commons" style="borderwidth:0" src="https://i.creativecommons.org/l/by/4.0/88x31.png" / $></ \mathrm{a}><$ br $/>$ Произведение «<span xmlns:dct="http:// purl.org/dc/terms/" href="http://purl.org/dc/dcmitype/Text" property="dct:title" rel="dct:type"> Неорганические

термостойкие связующие $</$ span $>$ » созданное автором по имени $<$ a xmlns:cc="http://creativecommons.org/ns\#"

href="Нанотехнологии в строительстве. - 2017. - Том 9, № 2. - C. 66-81. - DOI:dx.doi.org/10.15828/2075-8545-2017-9-2-66-

81" property="cc:attributionName" rel="cc:attributionURL" $>$ Кудрявцев П. Г., Фиговский О.Л. $</ \mathrm{a}>$, публикуется на условияx <a rel="license" href="http://creativecommons.org/licenses/by/4.0/">лицензии Creative Commons "Attribution» ("Атрибуция») 4.0 Всемирная $</ \mathrm{a}>$. $<\mathrm{br} />$ Основано на произведении с $<$ a xmlns:dct="http://purl.org/dc/terms/" href="http:// nanobuild.ru/ru_RU/nanobuild-2-2017/" rel="dct:source" $>$ http://nanobuild.ru/ru_RU/nanobuild-2-2017/</a $>$. $<$ br $/>$ Paspeшения, выходящие за рамки данной лицензии, могут быть доступны на странице $<$ a xmlns:cc="http://creativecommons.org/ ns\#" href="pgkudr89@gmail.com" rel="cc:morePermissions">pgkudr89@gmail.com</a> .

\section{Введение}

Неорганические связующие имеют преимущество по сравнению с органическими полимерными клеями из-за их способности выдерживать высокие температуры. Они чаще всего представляют собой аморфные вещества, такие как диоксид кремния. Некоторые связующие представляют собой вещества, находящиеся в виде наночастиц, например оксид алюминия, которые обычно диспергированы в жидком носителе. Такие дисперсии известны как коллоидные растворы. В процессе изготовления композиционного материала носитель испаряется во время нагревания. При этом связующее взаимодействует с наполнителем, с образованием областей скрепления компонентов наполнителя между собой. Таким образом, в области связи остаются только наночастицы связующего. В качестве альтернативы иногда могут быть использованы связующие в виде порошка, без носителя.

В последние годы получило интенсивное развитие направление в технологии керамики и неорганических композитов - формование 
материалов из растворов с использованием золь-гель процессов [19]. Естественно, в первом ряду таких материалов стоят продукты на основе кремнезолей, которые являются продолжением ряда жидких стекол, при устремлении силикатного модуля к бесконечности $[1,2]$. Сущность этих процессов заключается в применении золей - коллоидных растворов, соответствующих оксидов и оксигидратов металлов, обладающих способностью в определенных условиях превращаться из жидких систем в твердые продукты. С точки зрения керамической технологии наибольший интерес представляют процессы получения золей наиболее тугоплавких оксидов металлов и, в первую очередь, оксидов кремния, алюминия, циркония и др. [3].

Другим типом неорганического связующего являются продукты на основе жидких фосфатных растворов, таких как кислые фросфаты алюминия или хрома. Такими продуктами, например, являются системы, полученные растворением гидроксида алюминия $\left(\mathrm{Al}(\mathrm{OH})_{3}\right)$ в фосфорной кислоте $\left(\mathrm{H}_{3} \mathrm{PO}_{4}\right)$ при перемешивании и нагревании до приблизительно $150^{\circ} \mathrm{C}$. В качестве связующих чаще всего используются растворы, имеющие атомное отношение $\mathrm{P} / \mathrm{Al}$ более 3 [10]. Такой раствор протекает между поверхностями, подлежащими соединению. При нагревании полученного раствора (выше $500^{\circ} \mathrm{C}$ в течение 3 часов) в нем происходят химические реакции. В результате этих процессов он превращается в твердое вещество, которое действует в качестве связующего субстрата. Продукты реакции представляют собой твердые фазы, состоящие из различных фосфатов алюминия.

Одним из перспективных типов термостойких связующих для композиционных материалов являются связующие на основе гидроксонитратов и гидроксохлоридов алюминия. Это одни из самых крупнотоннажных продуктов. Годовой объем их производства в 2015 году составил около 170 миллионов тонн [5]. Более 90\% этого объема превращается в оксид алюминия, который используется в производстве металлического алюминия [17]. Получение основных солей алюминия было разработано для использования этих солей как связующих для грануляции адсорбентов на основе цеолитов [7], однако проведенные исследования показали перспективность использования данных соединений в качестве связующих при изготовлении конструкционных композиционных материалов. 


\section{1. Связующие на основе основных солей алюминия}

Коллоидно-химические и связующие свойства основных солей алюминия зависят от соотношения $\mathrm{Al} / \mathrm{NO}_{3}$ в их молекулах. С увеличением основности солей возрастает $\mathrm{pH}$, степень полимеризации и, соответственно, вязкость их растворов. При $\mathrm{Al} / \mathrm{NO}_{3}=1 / 2$ в растворе наблюдается опалесценция, и он реально является коллоидным раствором. При концентрации более $19 \%$ и мольном отношении $\mathrm{Al} / \mathrm{NO}_{3}>2$ растворы этих солей имеют гелеобразный вид.

Гидроксонитраты алюминия используют в качестве связующих в виде растворов или золей. Основные соли алюминия имеют следующий состав: $\mathrm{Al}(\mathrm{OH})_{2} \mathrm{NO}_{3}, \mathrm{Al}_{2}(\mathrm{OH})_{5} \mathrm{NO}_{3}, \mathrm{Al}_{3}(\mathrm{OH})_{8} \mathrm{NO}_{3}, \mathrm{Al}_{4}(\mathrm{OH})_{11} \mathrm{NO}_{3}$. Эти данные являются условными, так как их брутто-формулы не отражают наличие аква-, гидроксо-, оксо- и других групп, которые содержатся в структуре молекул основных солей. Указанные соединения алюминия готовят, растворяя свежеосажденный гидроксид алюминия в стехиометрическом количестве азотной кислоты. Для придания водостойкости материалу, полученному при использовании гидроксонитратов в качестве связующих (например, гранулы цеолитов), его подвергают прокаливанию при температуре $450 \div 550^{\circ} \mathrm{C}$. В результате термообработки образуется $\mathrm{Al}_{2} \mathrm{O}_{3}$, а прочностные свойства материала повышаются [8].

В соответствии с данными [10], разложение гидроксохлорида алюминия при нагревании протекает по следующей схеме:

$$
\begin{aligned}
& \mathrm{Al}_{2}(\mathrm{OH})_{5} \mathrm{Cl} \cdot 6 \mathrm{H}_{2} \mathrm{O} \stackrel{140 \stackrel{\mathrm{c}}{\longrightarrow}}{\longrightarrow} \mathrm{Al}_{2}(\mathrm{OH})_{5} \mathrm{Cl} \cdot 4,5 \mathrm{H}_{2} \mathrm{O}+1,5 \mathrm{H}_{2} \mathrm{O} \\
& \mathrm{Al}_{2}(\mathrm{OH})_{5} \mathrm{Cl} \cdot 4,5 \mathrm{H}_{2} \mathrm{O} \stackrel{200 \mathrm{\tau}}{\longrightarrow} \mathrm{Al}_{\mathbf{2}} \mathrm{O}_{3} \cdot \mathrm{H}_{2} \mathrm{O}+\mathrm{HCl}+5,5 \mathrm{H}_{2} \mathrm{O} \\
& \mathrm{Al}_{2} \mathrm{O}_{3} \cdot \mathrm{H}_{2} \mathrm{O} \stackrel{200-600 \varkappa}{\longrightarrow} \mathrm{Al}_{2} \mathrm{O}_{3}+\mathrm{H}_{2} \mathrm{O}
\end{aligned}
$$

Одним из простых способов получения гидроксохлоридов алюминия является термолиз $\mathrm{AlCl}_{3} \cdot 6 \mathrm{H}_{2} \mathrm{O}$ [12]. Водный раствор продуктов термолиза, по брутто составу отвечающий гидроксохлориду алюминия $5 / 6$, содержит некоторое количество примесей гидроксохлоридов алюминия другой основности. Этим способом можно получать продукты с отношением $\mathrm{Al} / \mathrm{Cl}$ от 1,1 до 2,3 и различной растворимостью в воде. Термические превращения продукта термолиза реализуются по схеме: 


$$
\begin{aligned}
& \mathrm{Al}_{2}(\mathrm{OH})_{5} \mathrm{Cl} \cdot 6 \mathrm{H}_{2} \mathrm{O} \stackrel{270 \varkappa}{\longrightarrow} \mathrm{Al}(\mathrm{OH})_{2} \mathrm{Cl}+\mathrm{AlO}(\mathrm{OH})+\mathrm{H}_{2} \mathrm{O} \\
& \mathrm{AlO}(\mathrm{OH}) \stackrel{370 \varkappa}{-} \mathrm{Al}_{\mathbf{2}} \mathrm{O}_{3}+\mathrm{H}_{2} \mathrm{O} \\
& \mathrm{Al}(\mathrm{OH})_{\mathbf{2}} \mathrm{Cl} \stackrel{270 \tau}{\longrightarrow} \mathrm{Al}_{\mathbf{2}} \mathrm{O}_{3}+2 \mathrm{HCl}+\mathrm{H}_{\mathbf{2}} \mathrm{O}
\end{aligned}
$$

Растворимость в воде 5/6 гидроксохлорида алюминия, полученного пептизацией свежеосажденного гидроксида алюминия хлористоводородной кислотой, повышается после его высушивания. Это явление связано с разрушением высокополимерных образований и образованием большего количества олигомерных частиц в получаемом продукте.

Использование гидроксохлоридных связующих позволяет получать более плотную корундовую керамику, чем при использовании связки на основе поливинилового спирта и других органических связующих. Исследование свойств гидроксосолей алюминия $\left(\mathrm{Al}_{2}(\mathrm{OH})_{n} \mathrm{X}_{6-n}\right.$, где $\mathrm{X}-\mathrm{Cl}^{-}$или $\mathrm{NO}_{3}^{-}$) показало, что хорошими связующими свойствами обладают гидроксосоли с $n=4,5$. При отклонении величины $n$, как в сторону увеличения основности $(n=5)$, так и в сторону увеличения кислотности $(n=4)$, связующая способность соответствующих соединений падает [10]. При применении гидроксо-солей алюминия основным соединением, выступающим в качестве связующей фазы, является низкотемпературная форма оксида алюминия $\gamma-\mathrm{Al}_{2} \mathrm{O}_{3}$, которая образуется при термической обработке соответствующих солей [13].

Благодаря вяжущим свойствам использование в качестве связующего гидроксохлорида алюминия обеспечивает надежное формование изделия-сырца. Кроме того, в результате термической деструкции поставляют в зону реакции сырьевые компоненты в активной форме, что способствует процессу спекания. С использованием гидроксохлорида алюминия были получены огнеупоры на основе магнезиального сырья и кварцевая керамика. Результаты испытаний этих материалов представлены на рис. 1.

\section{2. Связующие на основе основных солей переходных металлов}

Примером этого интересного класса неорганических связующих являются материалы на основе гидроксонитратов циркония. Известно, что у нитрата циркония в интервале температур от 110 до $250^{\circ} \mathrm{C}$ после 


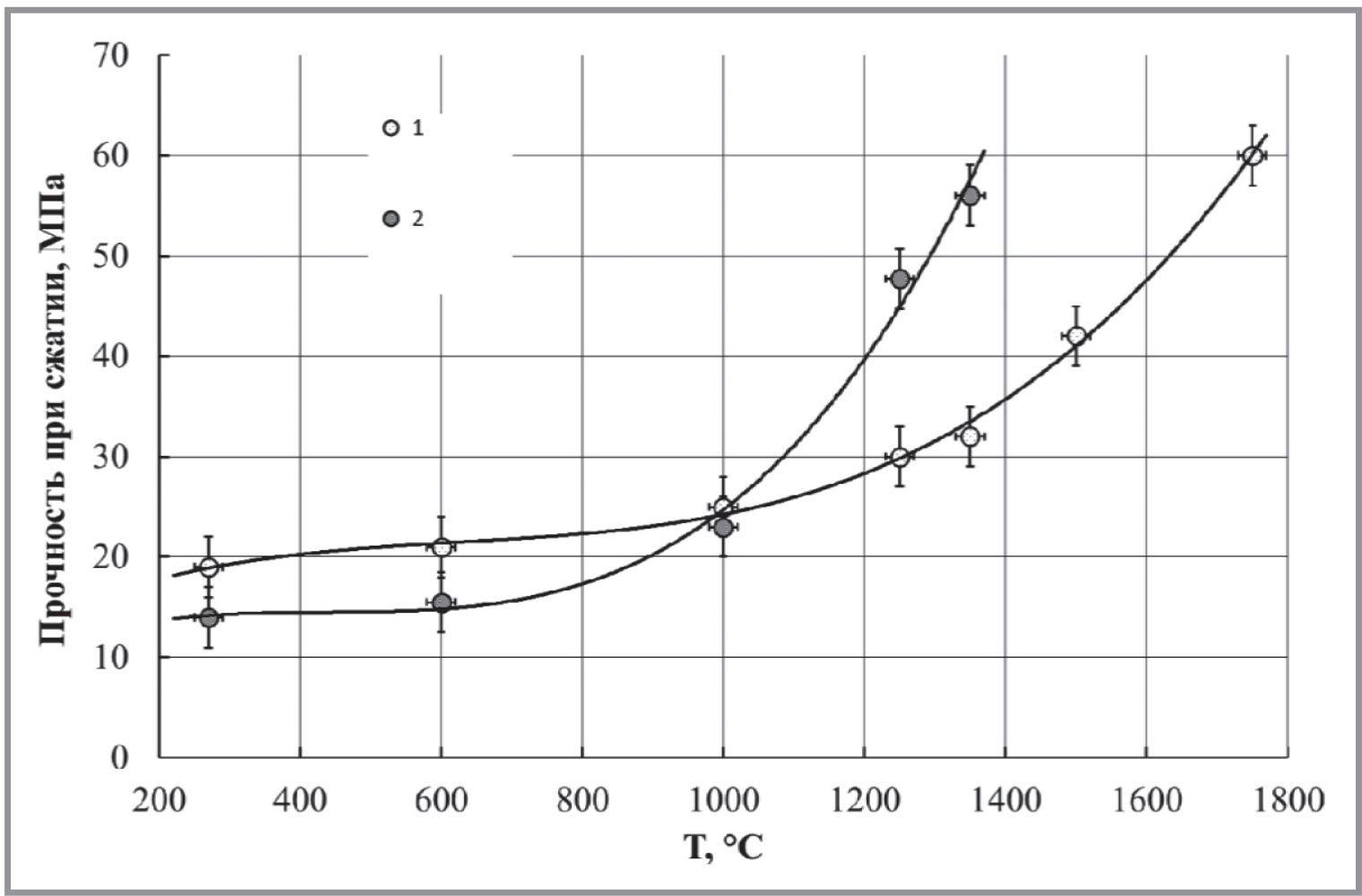

Рис. 1. Прочность материалов, полученных с использованием гидроксохлорида алюминия в качестве связующего: 1 - кварцевая керамика; 2 - магнезиальный огнеупор

удаления части групп $\mathrm{NO}_{3}$, у его катионных комплексов, происходит усложнение структуры. Кроме того, с увеличением концентрации соли в растворе возрастает степень их полимеризации. Исходя из этого были приготовлены связующие на основе раствора нитрата циркония с концентрацией $60 \%$ [14]. Раствор подвергали кипячению, что приводило к гидролизу соли циркония и образованию коллоидного раствора его гидратированного оксида, стабилизированного нитрат ионами. Полу-

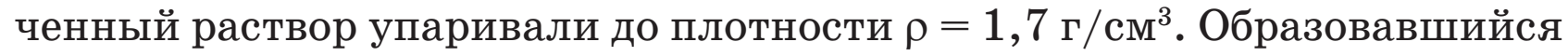
в результате вязкий опалесцирующий раствор являлся весьма устойчивым по времени и сохранял устойчивость при разбавлении. Полученное таким образом вязкое связующее содержит $33 \% \mathrm{ZrO}_{2}\left(\rho=1,65\right.$ г/ $\left.\mathrm{cm}^{3}\right)$, имеет в своем составе $30,8 \% \mathrm{NO}_{3}$, что отвечало мольному отношению $\mathrm{NO}_{3} / \mathrm{ZrO}_{2}=0,97$ против 2 в исходной соли циркония.

Результаты испытаний полученного связующего представлены на рис. 2. При нагревании такое связующее превращалось в высокоди- 


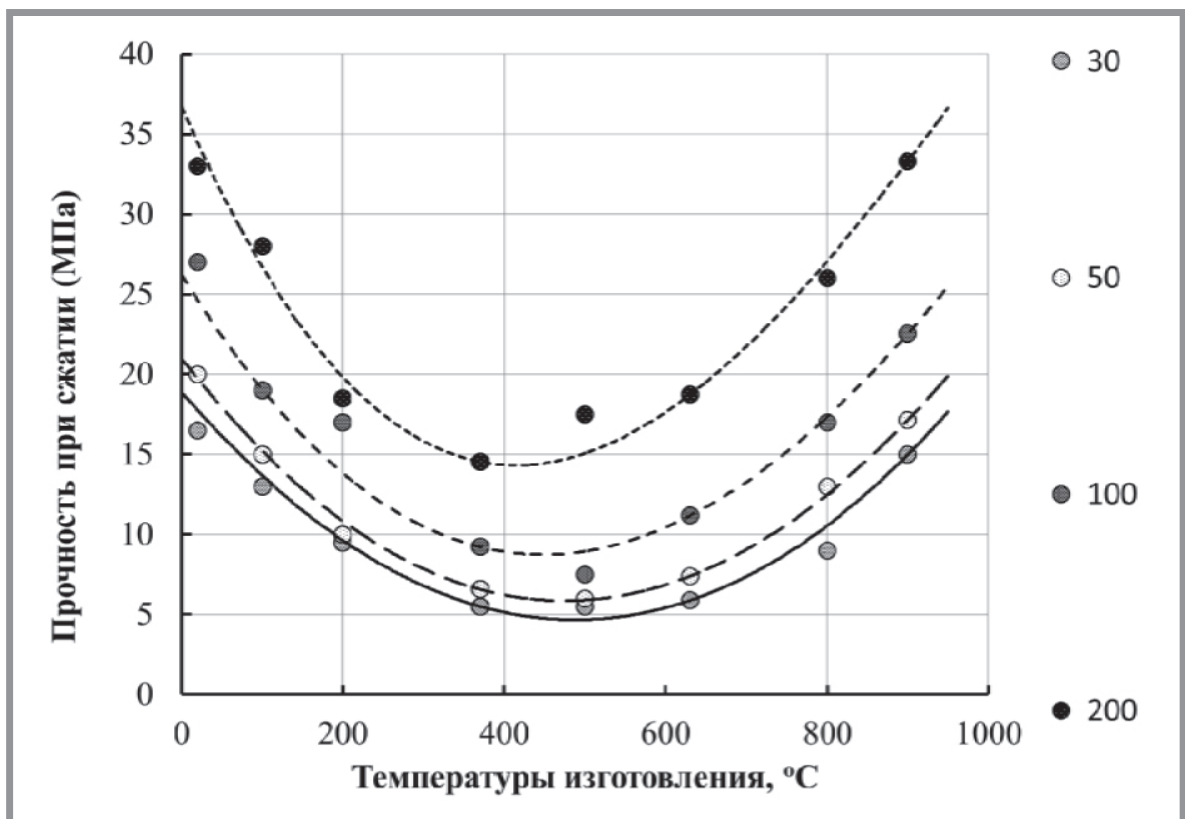

Рuc. 2. Использование связующего на основе гидроксонитратов циркония

для получения термостойких композиционных материалов. В качестве наполнителя использовался порошок циркона с размером частиц: $63 \div 160$ мкм.

Давление прессования при изготовлении материала: 30, 50, 100, 200 МПа

сперсный диоксид циркония. Применение этого связующего привело к улучшению спекаемости и уменьшению в два раза пористости изделий по сравнению с изделиями, полученными с использованием поливинилового спирта.

Вид представленных зависимостей указывает на то, что при изготовлении изделий наблюдается два взаимно противоположных процесса. Первый связан с потерей воды и остатков анионных групп и, соответственно, исчезновением координационных связей, обусловленных координацией воды и гидроксо-групп. Эти процессы протекают на начальном этапе термообработки и приводят к снижению прочностных характеристик материала с данным связующим.

Увеличение прочности материала при более высокой температуре обработки обусловлено вторым процессом. На этой стадии происходит активация процессов спекания и диффузионного переноса материала связующего. Протекание процесса спекания при весьма низкой температуре связано с высокодисперсным характером частиц связующего. При анализе полученных данных был обнаружен интересный эффект, 
который представлен на рис. 3. На этом рисунке представлено изменение положения минимума на кривых, представленных на рис. 2 , в зависимости от давления прессования, при изготовлении соответствующих изделий. Из него видно, что при повышении давления при изготовлении материала, положение минимума смещается в сторону низких температур. Этот эффект обусловлен уменьшением толщины пленки связующего между частицами наполнителя, и соответственно, увеличением скорости переноса вещества к межфазной границе и облегчению процессов спекания. Аналогичные материалы могут быть получены и при использовании хлоридных систем.

Свойства, подобные свойствам гидроксо-солей алюминия, имеют и соответствующие соединения циркония. Для синтеза гидроксохлоридов циркония свежеосажденный гидроксид циркония растворяли в концентрированной соляной кислоте, количество которой рассчитывали исходя из условия получения основных солей следующего состава $\mathrm{Zr}(\mathrm{OH})_{2} \mathrm{Cl}_{2}$ [9]. Полученные прозрачные растворы выпаривали до содержания $\mathrm{ZrO}_{2}-31 \div 35 \%$, при дальнейшем повышении концентрации наблюдается стеклование их растворов.

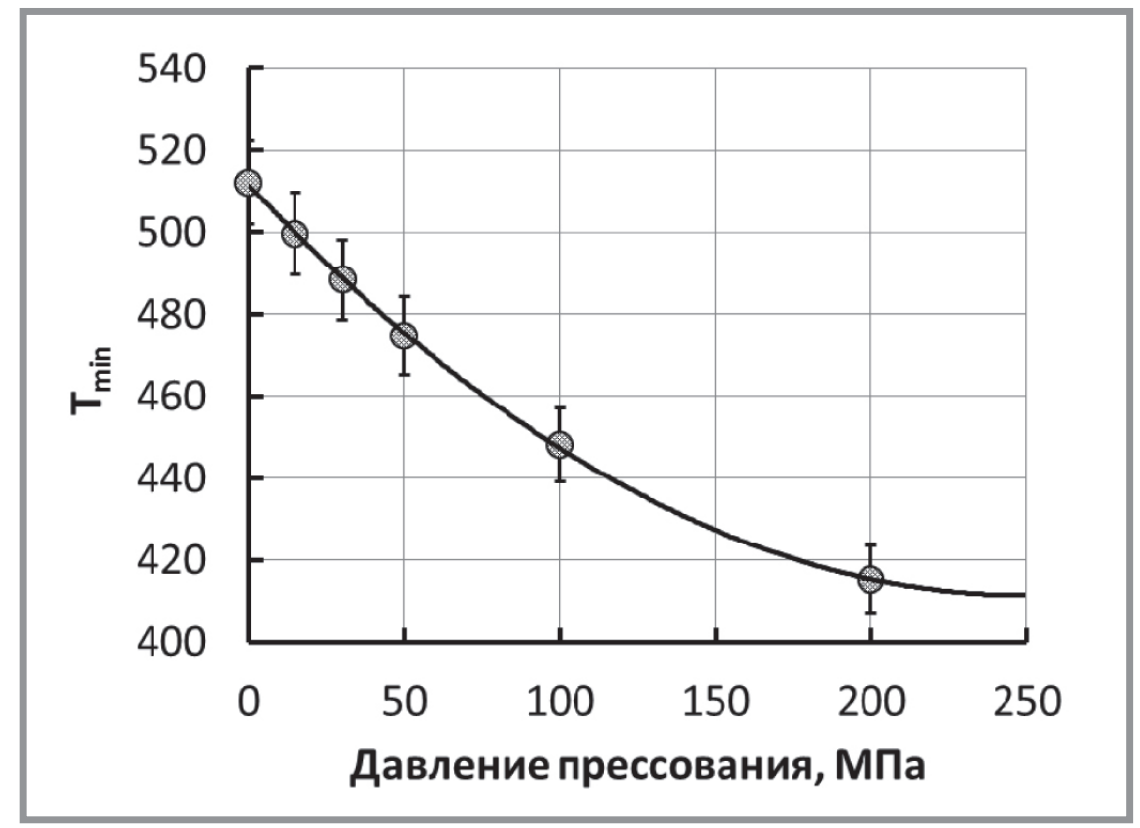

Рuc. 3. Изменение положения температурного минимума от величины давления прессования на кривых зависимости прочности материала от температуры спекания (рис. 2) при использовании гидроксо-нитратного циркониевого связующего 
Известны связующие на основе гидроксокомплексов хрома. В работе [15] были разработаны способы получения связующих на основе солей хрома. Соединения хрома хорошо изучены как дубители, причем установлена полимерная природа солей хрома. В зависимости от степени основности солей изменяется молекулярная масса и число атомов хрома в молекулах его нитратных солей: $\mathrm{Cr}\left(\mathrm{NO}_{3}\right)_{3},\left[\mathrm{Cr}_{2}(\mathrm{OH})_{2}\right]\left(\mathrm{NO}_{3}\right)_{4}$, $\left[\mathrm{Cr}_{2}(\mathrm{OH})_{3}\right]\left(\mathrm{NO}_{3}\right)_{3},\left[\mathrm{Cr}_{4}(\mathrm{OH})_{7}\right]\left(\mathrm{NO}_{3}\right)_{5}$.

При растворении гидроксида хрома в $\mathrm{HCl}$ или $\mathrm{HNO}_{3}$ удавалось получить вязкие растворы с основностью $83 \%$ при его растворении в $\mathrm{H}_{2} \mathrm{SO}_{4}$ до $60 \%$. При этом плотности растворов составляли около 1,65 г $/ \mathrm{cm}^{3}$, при более высокой концентрации в этих растворах происходило стеклование [16].

Для соединений хрома с различными анионами наблюдается рост их активности как связующих в ряду: $\mathrm{Cl}^{-}<\mathrm{NO}_{3}{ }^{-}<\mathrm{SO}_{4}{ }^{2-}$. При этом также растет и время их жизни. Имеется прямая корреляция между поляризуемостью аниона цементирующей фазы и прочностью получаемого материала. Повышенное содержание жидкой фазы в композиции также существенно снижает прочность получаемых материалов, что ранее наблюдалось у силикатных связующих [18]. Кроме того, прочность материалов растет с увеличением концентрации связующего при неизменной его основности [10]. Этот факт еще раз подтверждает эффект, который был обнаружен при получении материалов с использованием в качестве связующих гидроксо-нитратов циркония.

Связующее на основе гидроксо-сульфата хрома проявляет хорошие адгезионные свойства к меди и латуни $(2,0 \div 2,7 \mathrm{MПа)} \mathrm{и} \mathrm{удовлетвори-}$ тельные - к бронзе и стали $(0,7 \div 1,0 \mathrm{MПа})$.

Данный класс химических соединений не ограничивается только описанными выше соединениями. Так, в работе [11], были описаны связующие, полученные на основе гидроксохлоридов кобальта, никеля, меди, цинка, кадмия. Такие связующие являются аналогами гидроксохлоридов алюминия и также относятся к группе кислых связующих. По сравнению с гидроксосолями алюминия и циркония они имеют ряд недостатков: первые три элемента дают окрашенные соединения, a, кроме того, все они в присутствии оксидов кремния дают эвтектики с достаточно низкими температурами плавления. Это затрудняет их использование в термостойких огнеупорных композитах, хотя в некоторых особых случаях они могут успешно использоваться. Элементы 
с $3 \mathrm{~d}$-орбиталями и Сd образуют основные соли, хорошо растворимые в воде, которые представляют собой олигомерные комплексы, например, $\mathrm{Zn}_{2}(\mathrm{OH})_{2}^{2+}, \mathrm{Cd}_{2}(\mathrm{OH})^{3+}, \mathrm{Ni}_{2}(\mathrm{OH})^{3+}$. При повышении концентрации соли образуются группировки с более высокой степенью полимеризации. Эти связующие получают путем растворения соответствующих свежеосажденных гидроксидов в $\mathrm{HCl}$ при нагревании. Полученный таким образом раствор концентрируют упариванием. Таким путем удается получить связующие со степенью основности $15 \div 50 \%$ и плотностью $1,4 \div 1,8$ г $/ \mathrm{cm}^{3}$. Повышение плотности связующего увеличивает его вяжущую активность.

Еще одним интересным классом химических соединений являются гидроксохроматы различных элементов. Синтез гидроксохроматов алюминия, магния, циркония осуществляли растворением свежеосажденного гидроксида соответствующего элемента в концентрированном растворе хромовой кислоты $\mathrm{H}_{2} \mathrm{CrO}_{4} \cdot \mathrm{H}_{2} \mathrm{CrO}_{4}$ прибавляли до достижения необходимой степени основности [16]. Таким способом были получены гидроксохроматы со степенью основности $20 \div 50 \%$. В зависимости от степени основности гидроксохроматы обладают различной растворимостью в воде. В качестве связующих использованы концентрированные водные растворы солей следующих составов: $\mathrm{AlOHCrO}_{4}, \mathrm{Mg}_{2}(\mathrm{OH})_{2} \mathrm{CrO}_{4}$, $\mathrm{Zr}(\mathrm{OH})_{2} \mathrm{CrO}_{4}$. Эти соединения имеют наибольшую растворимость. Область существования основных солей заданного состава ограничивается определенным интервалом рН. Установлено, что для гидроксохромата алюминия интервал стабильности находится в области $\mathrm{pH}=4,5 \div 5$; магния $-6,5 \div 7$; циркония $-5,5 \div 6$. Концентрирование гидроксохромитных растворов может быть осуществлено выпариванием под вакуумом. Максимальной адгезией к различным наполнителям обладают растворы с концентрацией $50 \div 55 \%$ и плотностью $1,60 \div 1,65$ г $/ \mathrm{cm}^{3}$. При дальнейшем повышении концентрации растворы загустевают, а затем переходят в стеклообразное состояние.

Указанные выше соединения являются промежуточными между истинными солями и коллоидными растворами оксидов соответствующих элементов. Поэтому в качестве связующих могут быть также использованы золи тугоплавких оксидов металлов. По аналогии с основными солями оксидные золи могут также быть получены методом пептизации осадков соответствующих гидроксидов. Недостатками метода пептизации является сравнительно большой объем аппаратуры, 
который требуется для его осуществления, а также неполное диспергирование и существование агрегатов в получаемом золе.

Золи оксидов металлов могут быть также получены гидролизом соответствующих соединений этих металлов. Например, алюмозоль может быть получен гидролитическим разложением солей алюминия или алюминатов щелочных металлов, а кремнезоль - гидролитическим разложением щелочных силикатов [4]. Одним из перспективных процессов получения золей является гидролиз алкоксидов металлов и поликонденсация продуктов реакции $[5,6]$.

\section{Заключение}

На основе проведенных исследований было показано, что основные соли многих металлов могут быть использованы в качестве связующего при получении термостойких композиционных материалов на основе оксидных систем.

Основными продуктами термического разложения всех типов связующих, рассмотренных в настоящей работе, являются нанодисперсные высокоогнеупорные оксиды. Следует отметить, что материалы на основе систем, содержащих хром и некоторые другие элементы в переходных степенях окисления, имеют окраску. Вследствие этого они имеют худшие показатели по теплопроводности по сравнению с бесцветными материалами.

\section{Библиографический список:}

1. Figovsky O., Beilin D. Advanced Polymer Concretes and Compounds @ CRC Press, Tailor \&Francis Group, 2013, 245 pp.

2. Кудрявиев П.Г., Вольхин В.В. Золь-гель процессы и некоторые его технологические приложения, золь-гель процессы получения неорганических материалов: тез. докл. семинара // Пермь, 1991. - С. 3-5.

3. Кудрявиев П.Г., Кавалерова О.Б. Методы получения золей оксигидратов металлов, используемых в качестве связующих для формования неорганических композитов: Сб. научн. трудов // Композиционные материалы на основе дисперсных систем. - Екатеринбург: УрО РАН, 1994. - С. 21-29. 
4. Кудрявиев П.Г., Кавалерова О.Б., Казакова И.Л., Вольхин В.В. Получение и стабилизация растворов оксидов металлов // Золь-гель процессы получения неорганических материалов. - Пермь, 1991. - С. 33.

5. Получение оксида алюминия особой чистоты: обзорная информация // Серия: Реактивы и особо чистые вещества. - М.: НИИТХИМ, 1987. - 40 с.

6. Kudryavtsev P.G. Alkoxides of chemical elements - promising class of chemical compounds wich are raw materials for Hi-Tech industries; Journal «Scientific Israel - Technological Advantages», Vol. 16, N 2, 2014, p. 147-170.

7. Evans K.A. Properties and uses of aluminium oxides and aluminium hydroxides, in The Chemistry of Aluminium, Indium and Gallium, ed. A.J. Downs, Published by Blackie Academic, 1993, ISBN 075140103 X.

8. ЖЖурнал прикладной химии / РАН. - 1969. - Т. 12. - № 6. - С. 1325-1330.

9. Коларова Т.И., Корнеева Т.Ф. Получение связки на основе 5/6 оксихлорида алюминия // Нестроительные вяжущие вещества. - Л., 1975. - С. 52-56.

10. Сычев M.M. Неорганические клеи. - 2-е изд. - Л.: Химия, 1986. - 152 с.

11. Неорганические материалы / РАН, институт общей и неорганической химии им. Н.С. Курнакова. - 1979. - Т. 15, № 1. - С. 2067-2069.

12. Известия высших учебных заведений: Химия и химическая технология. 1982. - Т. 25, вып. 6. - С. 740-743.

13. ЖЖурнал прикладной химии / РАН. - 1969. - Т. 13, № 7. - С. 1485-1490.

14. Цемент. - 1975. - № 3. - С. 9-10.

15. Неорганические материалы / РАН, институт общей и неорганической химии им. Н.С. Курнакова. - 1978. - Т. 14, № 6. - С. 1153-1155.

16. Физическая химия и технология силикатных материалов. - Л.: ЛТИ, 1978. вып. 6. - С. 113-118.

17. Data published annually by World Aluminium, London, http://www.worldaluminium.org

18. Figovsky O., Kudryavtsev P. Advanced Nanomaterials Based On Soluble Silicates. Journal «Scientific Israel - Technological Advantages», Vol. 16, N 3, 2014 , p. 38-76.

19. Кудрявиев П.Г., Фиговский О.Л. Наноструктурированные материалы, получение и применение в строительстве. - Нанотехнологии в строительстве. 2014. - T. 6, № 6. - C. 27-45. - DOI: dx.doi.org/10.15828/2075-8545-2014-66-27-45. 
У ВАЖАЕМЫЕ КОЛЛЕГИ!

ПРИ ИСПОЛЬЗОВАНИИ МАТЕРИАЛА ДАННОЙ СТАТЬИ

ПРОСИМ ДЕЛАТЬ БИБЛИОГРАФИЧЕСКУЮ ССЫЛКУ НА НЕЁ:

Кудрявиев П. Г., Фиговский О.Л. Неорганические термостойкие связующие // Нанотехнологии в строительстве. - 2017. - Том 9, № 2. - С. 66-81. - DOI: dx.doi.org/10.15828/2075-8545-2017-9-2-66-81.

\section{DeAR COLleagues!}

THE REFERENCE TO THIS PAPER HAS THE FOLLOWING CITATION FORMAT:

Kudryavtsev P.G., Figovsky O.L. Heat-resistant inorganic binders. Nanotehnologii v stroitel'stve $=$ Nanotechnologies in Construction. 2017, Vol. 9, no. 2, pp. 66-81. DOI: dx.doi.org/10.15828/2075-8545-2017-9-2-66-81. (In Russian). 